\title{
12 Viral Carbohydrates, Proteins and Neutralization
}

\subsection{Carbohydrates and Neutralization}

Most neutralization antigens are proteins but viruses can also be neutralized by antibody to host antigens, probably carbohydrate. This is present primarily in the form of glycoprotein but enveloped viruses also have cellular glycolipids. Enveloped viruses have an unknown mechanism for excluding the bulk of host protein present in the membranes from which they bud, but it cannot be excluded that small amounts of host protein, usually designated as contaminants, are an integral part of the virus particle. Examples of neutralizing antibodies specific for host antigens are found in influenza virus (HAUKENES 1977), infectious bronchitis virus (ALMEIDA and WATERSON 1969), the lentivirus equine infectious anaemia virus (MONTELARO et al. 1990) and HIV-1 (HANSEN et al. 1991). However, as with anti-virus protein antibodies, binding is not necessarily synonymous with neutralization (influenza virus: BRESCHKIN et al. 1981). Mabs in particular give precise evidence of specificity and 4 to 20 were found to have neutralizing activity to HIV-1 (HANSEN et al. 1990), particularly those to mucin-type carbohydrate (HANSEN et al. 1991). However, viral carbohydrate is usually not immunogenic as it is provided by the cell and antibodies would only be generated during infection if immunological tolerance were broken. It is conceivable, though, that antibodies to bacterial carbohydrate crossreact with viral carbohydrate. The same strictures apply to the lipid component of viruses. Early data on the inhibition of influenza virus with antibody to host carbohydrate have to be interpreted with care since the antibody acted not on the virus particle but on the cell (LAVER and WEBSTER 1966), possibly by inhibiting virus attachment. More recent chemical data demonstrate that six of the oligosaccharide side chains covalently bound to the HA are antigenically related to the host (WARD et al. 1981).

Carbohydrate moieties may also alter the antigenicity of glycoproteins as revealed by deglycosylation (Rauscher leukaemia and influenza A viruses, ALEXANDER and ELDER 1984; tick-borne encephalitis virus, TBEV, GUIRAKHOO et al. 1989; bovine herpesvirus, VAN DRUNEN LITTEL-VAN DEN HURK et al. 1990 ) but the antigenicity of murine leukaemia virus was not affected when its carbohydrate was removed (PIEROTTI et al. 1981). However, deglycosylation of Rauscher leukaemia virus (ELDER et al. 1986), HIV-1 gp120 (PUTNEY et al. 1986) or flaviviruses (WINKLER et al. 1987) had no discernible effect on their antigenicity or immunogenicity. Some HIV-1-neutralizing mabs recognize non-glycosylated gp120 expressed in Escherichia coli (KINNEY- 
THOMAS et al. 1988). Carbohydrate may form part of an epitope or be necessary for a protein achieving its correct conformation (murine leukaemia virus, PIEROTTI et al. 1981; bovine leukaemia virus, Bruck et al. 1984; NDV, LONG et al. 1986; influenza C virus, SUgAWARA et al. 1988; LCMV, WRIGHT et al. 1989; Sendai virus, VIDAL et al. 1989; HIV-1, MOORE et al. 1990; Ho et al. 1991a). Virions containing carbohydrate-free influenza virus HA were efficiently precipitated by five different neutralizing mabs (BASAK and COMPANS 1983). VAN DRUNEN LITTEL-VAN DEN HURK et al. (1990) think that carbohydrate is an integral part of three epitopes of $\mathrm{gl}$, the main neutralization protein of bovine herpes virus. An antigenic site may be hidden or revealed by the acquisition or loss of a carbohydrate moiety (influenza virus, SKEHEL et al. 1984; SMITH et al. 1991; rotavirus, MACKOW et al. 1988; rabies virus WUNNER et al. 1985; mumps virus, GотOH et al. 1988; KÖVAMEES et al. 1990; human PIV-3 Coelingh and TIERNEY 1989b; HIV-1, DAVIS et al. 1990; HSV-1: MUGGERIDGE et al. 1990). Such changes may be an evolutionary ploy which ensures survival in the host species or in individuals (Sect. 22.2.1). RASMUSSEN et al. (1988) believe that carbohydrate has another function and acts to protect the neutralization protein, $\mathrm{p} 86$, of $\mathrm{HCMV}$ from protease degradation.

Currently there is considerable interest in the development of vaccines to HIV, and much is being made of the SIV-primate model (DESROSIERS et al. 1989; MURPHEY-CORB et al. 1989, 1991; STOTT et al. 1990). However, there is suspicion that protection depends, at least in part, upon immunity generated to host components present in the challenge virus (STOTT 1991; LE GRAND et al. 1992, and see GROOPMAN 1991 ) since (a) protection does not correlate with antibody to SIV (DESROSIERS et al. 1989; MURPHEY-CORB et al. 1991; CARLSON et al. 1990), (b) there are high levels of antibody against cellular components, (c) animals can be protected by immunization with noninfected cells of the same species as those in which the challenge virus was grown, and (d) protected animals have about 10-fold more anti-cell antibody than those which were not protected (STOTT et al. 1990). Further, monkeys were also protected by immunization with a heterologous virus grown in the same cells as the challenge SIV (CRANAGE et al. 1992).

At the time of writing only preliminary data are available and it is not certain if antibody or cellular immunity is primarily responsible for protection, or if protein or carbohydrate epitopes are involved. Crossreaction between anti-cell antibodies and SIV particles is another possibility.

Conc/usion. Carbohydrate moieties may have a variety of functions - or no function - in neutralization.

\subsection{Proteins and Neutralization}

Most viruses of vertebrate animals have two or more proteins in their outer structure. Exceptions are the Rhabdoviridae, Retroviridae and Arenaviridae, members of which have a single glycosylated envelope protein which mediates 
neutralization. At least one protein mediates attachment, but other proteins (e.g. the NA of influenza virus) may be needed for release of progeny virions from the cell. Evolution of multiple outer proteins may also provide a necessary flexibility of response to the pressures exerted by the immune response. Unlike phages, where attachment is mediated through a minority of the total surface protein and in some instances by one or a few molecules, animal viruses have a substantial proportion of their surface proteins able to perform this function.

Of the two or more proteins which most animal viruses present on their outer surface, one or more mediates neutralization. This in part depends on the division of function between viral proteins; for example, the business of infection may be the property of one protein (HA of influenza virus: WILEY and SKEHEL 1987) or of at least four proteins (gB, gC, gD, gH of HSV-1: Sects. 2,3). A single protein may have several distinct neutralization sites (for example, up to eight in the envelope protein, gp51, of bovine leukaemia virus BRUCK et al. 1982a) which may be linear in sequence, with or without a requirement for a specific conformation, or discontinuous (Sect. 13). There are many examples of viruses with two or more neutralization proteins and those given below are intended only to illustrate the principles involved.

Influenza virus has two surface proteins, the haemagglutinin (HA) and the neuraminidase (NA), which act independently in neutralization. The HA of subtype $\mathrm{H} 3$ has five potential neutralization sites (A-E, Fig. 1), all of which are conformational (WILEY et al. 1981; DANIELS et al. 1983). It is remarkable that of the many HA-specific mabs isolated, so few are non-neutralizing (BRESCHKIN et al. 1981; PHILPOTT et al. 1989); this is not an artefact of selection in the sense that neutralization is rarely used as criterion. BRESCHKIN et al. (1981) has competition mapped a non-neutralizing mab to one of the neutralization sites, but this site was not assigned to the physical structure; unfortunately the mab no longer exists. GERHARD et al. (1980) report mabs which bind the HA but do not inhibit haemagglutination except at high concentration ( $>10-130 \mu \mathrm{g} / \mathrm{ml}$ ); no neutralization data were recorded. The HA is a homotrimer (WILEY et al. 1977) and some epitopes of sites B and D depend on its quaternary structure (BROWN et al. 1990). Neutralization of virions by antibody to the other major glycoprotein, the NA, is weak (SETO and ROTT 1966; WeBSTER and LAVER 1967; WeBSTER et al. 1968) and in appropriate proportions is mediated by aggregation (COMPANS et al. 1969; KENDAL and MADELEY 1970). Anti-NA also prevents release of virus from the vicinity of the cell (Sect. 16). In paramyxoviruses, attachment and entry (by fusion at the plasma membrane) are largely, but not entirely, separate functions of the $\mathrm{HN}$ and $\mathrm{F}$ proteins and both can mediate neutralization (see Sect. 5.3 and NORRBY 1990).

Herpesviruses have several neutralization proteins. Four of the surface glycoproteins ( $\mathrm{gB}, \mathrm{gC}, \mathrm{gD}$ and $\mathrm{gH})$, which are believed to be separate entities, can mediate neutralization. Anti-gB, anti-gC and anti-gD each block attachment but do so very inefficiently (see Sect. 2). Anti-gB, anti-gD and anti-gH can each block entry. It is not known precisely what function(s) 
are inhibited but the fact that attachment is blocked by antibodies to three different proteins may imply that $\mathrm{gB}, \mathrm{gC}$ and $\mathrm{gD}$ each contributes to the same process, or that each contributes to a different part of the same attachment process or that there is cooperativity in neutralization so that antibody to one protein abolishes (by steric or conformational influence) the activities of the others. The same argument applies to the dual functions of attachment and penetration performed by $\mathrm{gB}$ and $\mathrm{gD}$; some evidence that $\mathrm{gB}$ has separate functions is provided by PEREIRA et al. (1989), who found that neutralizing anti-gB mabs react with the $\mathrm{N}$-terminal domain or a mid-region domain. They suggest that the former is involved in low-affinity attachment to heparan sulphate (WUDUNN and SPEAR 1989) and the latter with penetration (HIGHLANDER et al. 1988).

The close packing of protein subunits of non-enveloped viruses offer opportunities for interactive events between consituent polypeptides which are less obvious in enveloped viruses, Poliovirus, for example, has three external polypeptides, VP1, VP2 and VP3. Most epitopes have a strong conformational element and the five antigenic sites involve VP1, VP2 and VP3 either alone or in permutation (see Table 11). There are a few mabs or sera which recognize isolated VP1, VP2 or VP3 and neutralize (see MINOR 1990), suggesting that some linear epitopes are also biologically active.

Adenovirus can be neutralized by IgG directed against any of the three constituents of the surface of the virion, the hexon, penton base and fibre proteins. In each case the mechanism of neutralization is different: none of the antibodies inhibited attachment, and anti-penton fibre actually increased attachment of neutralized virus to the cell; only anti-penton fibre inhibited internalization. After internalization, the genome of virus neutralized by antihexon and anti-penton base became DNase sensitive, as is normal with infectious virus, but most virus neutralized by anti-hexon remains in endocytic vesicles while only about $50 \%$ of that reacting with anti-penton base is so located. Anti-penton base is poorly neutralizing (to $45 \%$ ), suggesting that it may block only one of several routes of entry into the cell (WOHLFART et al. 1985).

Rotaviruses have an outer shell composed of VP7 and the spike protein VP4 (until recently known as VP3). The latter has been visualized in combination with Fab by cryoelectronmicroscopy (PRASAD et al. 1990). IgG to both VP4 and VP7 is neutralizing but the situation is complex as some antiVP7 mabs inhibit attachment and some do not, and some anti-VP4 mabs inhibit attachment and some do not (KUKUHARA et al. 1988; SABARA et al. 1985; RUGGERI and GREENBERG 1991).

Not all surface proteins function in neutralization-at least in vitro. Influenza virus was not neutralized by a mab prepared to a peptide of an external epitope of the M2 protein (ZEBEDEE and LAMB 1988), and antiserum to the HA2 transmembrane polypeptide of the major spike protein of influenza virus does not bind to infectious virus (GRAVES et al. 1983) or to virions budding from the surface of infected cells even though it inhibits haemag- 
glutination by isolated HA (BECHT et al. 1984). Mabs to the transmembrane polypeptide GP-2 of LCMV do not neutralize (PAREKH and BUCHMEIER 1986; BURNS and BUCHMEIER 1991), but mabs specific to the analogous S2 protein of coronaviruses neutralize (LUYTJES et al. 1989; KOCH et al. 1990; WEISMILLER et al. 1990; ROUTLEDGE et al. 1991) or do not neutralize (LAUDE et al. 1986; CAVANAGH et al. 1986). Other membrane-anchoring proteins also function as neutralization antigens (gp41 of HIV-1, see Figs. 2,10; F1 of NDV, TOYODA et al. 1988). Their ability to mediate neutralization may depend on their immunogenicity and/or their accessibility to antibody once it is formed; alternatively they may have no role in neutralization at all. In this regard HIV-1 gp41 may be unusually accessible as spikes are relatively sparse (70-80 per virion compared with 500-1000 per virion for the similar sized influenza particle) and the distal element of the spike protein, gp120, is easily sloughed off (GELDERBLOM et al. 1987).

Conclusion. Most viruses have more than one outer protein which mediates neutralization, and this contributes to the complexity of neutralization. Often each has multiple neutralization sites and probably different mechanisms of neutralization. The efficiency of neutralization may vary between proteins. 